\title{
Automatic seismic swarm analyzer system based on template matching algorithms and Master-Cluster relative location methods
}

Eduardo Andrés Díaz Suárez ${ }^{1}$ (eadiaz@mitma.es, @EADSuarez) Itahiza Dominguez Cerdeña ${ }^{1}$ (ifdominguez@mitma.es, @ita_dc) Carmen del Fresno ${ }^{2}$ (cdelfresno@mitma.es)

${ }^{1}$ Instituto Geográfico Nacional, Santa Cruz de Tenerife, ES ${ }^{2}$ Instituto Geográfico Nacional, Madrid, ES

This manuscript has been submitted for publication in Geophysical Journal International and is undergoing peer-review. Please note that the manuscript has not been formally accepted for publication. Subsequent versions of this manuscript may have slightly different content. If accepted, the final version of this manuscript will be available via the Peer-review Publication DOI link on this webpage. Please feel free to contact the authors; We welcome feedback. 


\title{
Automatic seismic swarm analyzer system based on template matching algorithms and Master-Cluster relative location
} methods

\author{
Eduardo Andrés Díaz Suárez ${ }^{1}$, Itahiza Dominguez Cerdeña ${ }^{1}$, Carmen del Fresno ${ }^{2}$ \\ ${ }^{1}$ Centro Geofísico de Canarias, Instituto Geográfico Nacional (IGN), España.E-mail:eadiaz@mitma.es \\ ${ }^{2}$ Observatorio Geofísico Central, Instituto Geográfico Nacional (IGN), España
}

Received -; in original form -

\section{SUMMARY}

Seismic swarms may have periods of intense activity with a high number of earthquakes per hour, with overlapping events and/or low signal-to-noise ratio seismic records. During these intervals, the manual characterization of the activity can become very complex to perform by seismic or volcanic observatories, resulting in inhomogeneous seismic catalogs. In order to tackle this problem, we have developed a set of automatic algorithms capable of detecting earthquakes, picking their $\mathrm{P}$ and $\mathrm{S}$ arrivals and locating the events with absolute and relative methodologies. Detections are performed over the filtered seismic energy while phase picking is based in the correlation of new events with a set of previous well-characterized templates. Absolute locations are computed using traditional algorithms as Hypoellipse and for relative locations we introduce a novel technique Master-Cluster, which is a hybrid between the double differences and the master event.

The algorithms have been tested on real data of two series corresponding to two different tectonic regimes: the volcanic pre-eruptive swarm of El Hierro, Spain (2011) and the tectonic seismic series of Torreperogil, Spain (2012-2013). Both data sets are considerably different in terms of epicentral distances and distribution of the network varying from stations very close to the activity at El Hierro $(5-20 \mathrm{~km})$ to regional distances in the case of Torreperogil (10-180km). 
The templates were taken as a partial dataset of 3600 (El Hierro) and 800 (Torreperogil) relocated earthquakes from the manual regional catalog. Based on these datasets, the algorithm was able to improve the number of events by a factor of 6 in El Hierro and 10 in Torreperogil, producing a seismic catalog between 3 and 4.5 times larger than the manually obtained one. An additional test was performed with the smaller earthquakes (local magnitude $<1.5$ ) which were not included in the set of templates, resulting not only in a good factor of success -larger than $65 \%$ of events were retrieved in both series- but also an enhancement in their automatic locations was observed with a more clustered seismicity than the previous catalog.

Key words: Time-series analysis, Computational Seismology, Statistical Seismology

\section{INTRODUCTION}

2 In the last two decades, there has been a significant leap in the seismic monitoring networks throughout the world (Mignan \& Chouliaras 2014; Dondin et al. 2019). Lower cost and optimization of real time data transmission systems and instrumentation (Jourdan \& de Weck 2004: 5 Werner-Allen et al. 2008; Lopes Pereira et al. 2014) has allowed the densification of the seismic 6 monitoring networks, and the volume of data generated has increased exponentially. This has led to a substantial improvement in real-time seismic monitoring, seismic hazards mapping and knowledge of the local and regional dynamics of seismically active zones (Benz 2017; Bianchi et al. 2018; Bent et al.2018). As a consequence, the capability to characterize and analyze the low mag10 nitude seismicity has improved and established as a new focus of study (Cesca \& Grigoli 2015, 11 Grigoli et al. 2017). During seismic swarms, there are considerably more low magnitude earth12 quakes than high magnitude earthquakes (Gutenberg \& Richter 1944). Therefore, real-time man13 ual analysis of seismic swarms can become an impossible task with dramatic consequences: First, ${ }_{4}$ low completeness seismic catalogs may lead to a misinterpretation of the ongoing phenomenon. ${ }_{15}$ Second, late warning to the population of the hazard associated to seismic swarms such as high magnitude earthquakes or volcanic eruptions that could be forecasted by precursory seismic activ7 ity.

A large amount of techniques for earthquake detection and phase picking have been developed 

${ }_{46}$ computational time consumption.

over the years. The first approximation for automatic detection was introduced by Allen (1982), comparing variations in ratios between long-term and short-term energy windows, known as the classical STA/LTA. Subsequently, several methodologies were proposed, such as the application a STA/LTA to signal envelopes (Baer \& Kradolfer 1987), or more complex studies of signal Gaussianity variations as a function of high order statistical parameters such as kurtosis and skewness (Saragiotis et al.2002; Küperkoch et al.|2010). In recent years, several techniques have been developed based on the use of reference templates for earthquake characterization and, in particular, microseismicity. Usually, the templates selected are waveforms manually analyzed by a seismologist that faithfully represent a group or the totality of the seismicity. These methods can be separated into two main groups: cross-correlation techniques (Chamberlain et al. 2017; Vuan et al. 2018; Chamberlain et al. 2020; Beaucé et al. 2017; Senobari et al.|2019) and neural network techniques (Zhu \& Beroza 2018; Perol et al. 2018; Liu et al. 2020). These methodologies are based on phase picking, however, there are several alternative techniques that perform the analysis of seismic signals based on the 'brightness" function of signals from a network of seismic stations (Kao \& Shan 2004, 2007; Journeau et al. 2020). Most methodologies provide a solution for the simultaneous detection, characterization and localization of seismicity but with a large computational cost and, generally, without a phase characterization.

In this paper, we introduce a new automatic seismic swarm analysis system tested on two different seismic series. The objective of this system is to simplify and enhance the analysis carried out in seismic and volcanic observatories by performing the detection, phasing and earthquake localization. The detection is performed using the classical STA/LTA algorithm applied over the spectrograms of the seismic signals of our network. Afterwards, a matched-filtering algorithm performs the phase picking, using earthquakes manually analyzed as templates. Once the phases are obtained, direct inversion is performed and the location is obtained using Hypoellipse (Lahr|1999). At the same time, using the methodologies of double differences, the algorithm improves the localization relocating the new detected earthquakes employing the template locations as multiple master events. The pipeline has been designed to allow full parallelization in order to optimize the 
EAD Suarez et al.

66 Energy $=\sum_{j=0}^{N-w}\left[\frac{1}{w} \sum_{i=j}^{j+w} x[i]\right]^{2}$ ${ }_{71}$ potential earthquake. 
${ }_{83} \quad R=\frac{t_{p}-f_{n}}{N_{d}}$

${ }_{84}$ And the second one, the $F_{1}$-Score:

${ }_{85} \quad F_{1}=\frac{t_{p}}{t_{p}+\frac{1}{2}\left(f_{p}+f_{n}\right)}$ optimize are: final set of parameter combinations.

\subsection{P and S Phase Picking}

The STA/LTA algorithm is very popular in the literature due to its simplicity and Robustness. However, determine the optimum window length of the STA and LTA and the threshold-detection, could be overwhelming. Those parameters depend on diverse features as the noise levels, the sensibility of our seismometers or the filter used in data processing. Therefore, an optimum calibration is obtained using a few hours of manually picked data as reference.

All the permutations are evaluated for a range of window lengths and thresholds, choosing the best solution as the one that obtains the best perform for two binary classifiers (Murphy 2012), $R$ and $F_{1}$, in a certain data set. The traces selected to calibrate the detectors have to fairly reproduce the main characteristics of the seismic activity to analyze. Defining $t_{p}$ as true positives, $f_{n}$ as false negatives, $f_{p}$ as false positives and $N_{d}$ manually detected earthquakes, the two parameters to

Both parameters weight the true positives above all the detections. While $R$ penalizes the false negatives above all the detections, as an absolute ratio, $F_{1}$ measures the relation between the true positives and the false performance of the detection, as a relative ratio. Once the detector has been calibrated, the final parameters are tested in a new manually detected trace, in order to check the

During seismic swarms, earthquakes are usually clustered in small regions having similar focal mechanisms. Ray tracing and radiation pattern may be almost identical for several events, their waveforms may be highly correlated and earthquakes can be classified in a small number of families (Okada et al. 1981). Cross correlation and template matching techniques, have been successfully applied previously to tectonic and volcanotectonic seismicity (e.g., Okada et al. 1981; Umakoshi et al. 2008; Carmona et al. 2010; Domínguez Cerdeña et al. 2011, Chamberlain et al. 
2020). Therefore the phase-picking is carried out by seismic waveform cross correlation in different stages.

\section{TEMPLATE CLASSIFICATION}

Our algorithm works using previous analyzed earthquakes, preferably well-characterized as a template set of data (i.e., catalog earthquake with magnitude above certain value or a minimum number of phases / stations).

A first step is to classify the template earthquakes into different families by waveform crosscorrelation. This classification have been used successfully for the seismicity of many volcanoes (Okada et al. 1981; Lahr et al. 1994; Stephens \& Chouet 2001). Events from a single family should produce very similar focal mechanism and be grouped within a small volume.

To classify each cluster, we calculate the normalized full wave cross correlation between all templates at each station. A correlation matrix $c c_{i, j}$ is obtained, where $i$ and $j$ are the template indices. The correlation matrix in time space can be defined as signals convolution:

$$
c c_{i, j}(\tau)=\frac{\sum_{t=0}^{N} x_{i}(t) \circledast x_{j}(t+\tau)}{\sqrt{\sum_{t=0}^{N} x_{i}^{2}(t) \cdot \sum_{t=0}^{N} x_{j}^{2}(t+\tau)}}
$$

where $x_{i}(t)$ and $x_{j}(t+\tau)$ are demeaned. The cross correlation matrix is obtained for each station used. Those matrices are added and normalized to one matrix which stores the information of the addition of each cross-correlation per event. Setting a threshold level for the normalized cross correlation coefficient (NCCC), templates are associated in families applying hierarchic analysis (e.g., Domínguez Cerdeña et al. 2011).

The phase picking is performed by cross correlation between the detected and the templates. For each earthquake detection, the algorithm segments and filters the data between two frequencies, $f_{\min }$ and $f_{\text {max }}$. The phase picking is developed in two steps, which will determine the quality of the picking. 


\section{Robust Phases}

Robust Phases are obtained by cross correlation of the full waveform which includes $\mathrm{P}, \mathrm{S}$ and surface wave data. We correlate each $i$-event detected with all the templates, in each $k$-station. Those pairs detection-template with NCCC that exceeds a threshold, are employed to calculate the arrival time, for $\mathrm{P}$ and $\mathrm{S}$ wave, as a weighted average. The cross-correlation coefficients used as weights are renormalized as Got et al. (1994):

$c c_{i, j}^{r}=\sqrt{\frac{\frac{c c_{i, j}}{1-c c_{i, j}^{2}}}{\frac{c c_{\max }^{2}}{1-c c_{\max }^{2}}}}$,

where $c_{i, j}$ are the NCCC obtained by Eq. (4) between $j$-template and the $i$-event, $\mathrm{c}_{\max }$ the larger $c_{i, j}$ and $c c_{i, j}^{r}$ the renormalized cross correlation coefficient (RNCCC). Then, P and S Robust Phases are determined for the $i$-event detected in the $k$-station.

Time lags and NCCCs between this earthquake and each of the templates are also stored. In consequence, after this step, we can classify each detected event and assign it to the family (or the group of families) with highest correlation.

\section{Fine Phases}

Calculation of Fine Phases is the second step in the phase picking process. The algorithm segments the $\mathrm{P}$ and $\mathrm{S}$ waveform of the templates to correlate them, separately. Subsequently, the P and S Robust Phases can be refined by correlate them with the P and S templates.

The $\mathrm{S}$ phases are correlated in horizontal components and the $\mathrm{P}$ phase in the vertical ones. The detection window length to correlate the templates is predefined, as well as the threshold to take them to account to refine the picks. Following the same procedure, the NCCCs are renormalized to the maximum NCCC obtained using Eq. (5) for each phase. If the templates correlates above the threshold, Fine Phases are obtained as a weighted-average. 


\section{Schedule}

The algorithm computes the phase picking through all the data available using initial parameters set by the user. It considers a successfully picked earthquake when phases are obtained in a minimum number of stations.

We have set this minimum to 3 , therefore, when that condition is met, the detected earthquake is ready to be located and the phase picking process will be set as finished. Phase picking module is schedule to start working in a main branch and, if the conditions are not fulfilled, it continues working in an alternative branch with lower thresholds.

Main branch tries to pick $\mathrm{P}$ and $\mathrm{S}$ phases by full wave cross correlation as has been described before. Regional earthquakes (at larger distances than $80 \mathrm{~km}$ ) may increase the difference between $\mathrm{P}$ and S arrivals and decrease the NCCC. Therefore, for regional stations (distances higher than $80 \mathrm{~km}$ from the epicenter), the Robust Phases are obtained as Fine Phases procedure but with slightly variations. To determine the $\mathrm{P}$ and $\mathrm{S}$ arrival time to segment the waveform, we calculate the theoretical arrival time, $t_{i, k}^{m}$ :

$t_{t e o, k}^{m}=t_{d e t, k^{\prime}}^{m}+t_{k}^{m}-t_{k^{\prime}}^{m}$,

where $t_{d e t, k^{\prime}}^{m}$ is the detection time in the nearest station $k^{\prime}$ to the seismicity for the $m$-wave (P or $\mathrm{S}$ wave) and, $t_{i, k}^{m}-t_{i, k^{\prime}}^{m}$ is the theoretical arrival difference between the nearest station $k^{\prime}$, and the regional station $k$. Then, the $\mathrm{P}$ and $\mathrm{S}$ waveforms are cross correlated with all the templates as Fine Phases process. Finally, if Robust Phases are obtained, the algorithm tries to estimate Fine Phases.

\subsection{Localization and Master-Cluster Method}

The hypocentral location is computed using Hypoellipse (Lahr 1999). A weight is assigned to the phases depending on which procedure have been applied to obtain them: we have used for Fine Phases the highest value (0), and second highest (1) for Robust Phases.

Classical techniques like this are the first approach to the location solution, however, they may have multiple sources of error when dealing with low magnitude events and can lead to 
large error ellipses. Results may show a strong dependence on the velocity models, the number of phases and the network azimutal coverage, giving large error ellipses. An example where these methodologies could have mislead to a low quality hypocentral location, could be a volcanic island where the aperture of the seismic network is smaller than the earthquakes depth and the unknown velocity model is far from the commonly used plane parallel model. For this reason, we propose to complete the analysis using a relative relocation of the data in our methodology.

Relative location techniques allow to obtain hypocentral locations with higher precision than the traditional methods. We have developed the new Master-Cluster method, which is midpoint between two well-known relocation methods, the double-difference (Waldhauser \& Ellsworth 2000) and master event (Ito 1985). The locations of our templates are known (obtained by classical or relative methods). Those locations can be considered as multiple master events if they correlate with our problem earthquakes. In other words, the double-difference technique can be applied to locate or relocate each problem earthquake but giving a fix location for the templates used. Then, the time residuals to minimize $d r_{k}^{i j}$ between the $i$-event and the $j$-template for a $k$-station can be expressed as:

$d r_{k}^{i j}=\left(t_{k}^{i}-t_{k}^{j}\right)^{t e o}-\left(t_{k}^{i}-t_{k}^{j}\right)^{c a l}=\frac{\partial t_{k}^{i}}{\partial x} \Delta x^{i}$

where $\left(t_{k}^{i}-t_{k}^{j}\right)^{t e o}$ corresponds to the theoretical time differences between the templates noted as $j$, and the $i$ problem earthquake for an observed phase in a $k$ station. The term $\left(t_{k}^{i}-t_{k}^{j}\right)^{c a l}$ are the cross correlation time lag between the templates and the earthquake to relocate for an observed phase at the $k$ station. The model is introduced in the equation as a partial derivative, $\partial t_{k}^{i} / \partial x$, which contains all the information of angles and velocity layers. Finally, the $\Delta x^{i}$ are the temporal and spatial corrections to apply to the original location of our earthquake and the RNCCC are used as weights in our system of equations

\section{Error estimation}

Since the relocation process is not a linear method, the error estimation has to be obtained applying other techniques. We chose the bootstrap analysis (Efron 1982) which has been successfully applied in other studies (e.g., Domínguez Cerdeña et al. 2014; Trugman \& Shearer 2017). The ap- 
plication of the bootstrap method consists in a statistical resampling of the relocation method, done $N$ times, and adding or subtracting randomly the residuals obtained for Eq. 7 to cross correlation timelag $\left(t_{k}^{i}-t_{k}^{j}\right)^{c a l}$. For each earthquake, an $N$-size distribution is obtained. As the distribution could have a strong bias or not be correctly described by a normal distribution, other authors (Leys et al.2013) introduce the median absolute deviation as an error estimator.

$\operatorname{err}(x)=\operatorname{Median}\left(\left|x_{i}-\operatorname{Median}(x)\right|\right)$,

where $x$, corresponds to any of the hypocentral coordinates. The robustness of this nonparametric estimator, avoids the standard deviation problems as biases or skewness (Mammen|1992; Maronna 2011; Hesterberg et al. 2005, e.g.).

\section{Workflow}

In order to solve the Eq. (7) by an iterative approach an initial location is needed. The inverse of $\partial t_{k}^{i} / \partial x$ can be calculated using singular value decomposition and the equations system is weighted with the cross correlation renormalized coefficient (Eq. (5p)).

As an initial solution, we could use the Hypoellipse results for each earthquake, however, due to the low quality of some phases, the hypocenter results are sometimes too far from the templates location. In order to solve this fact, our algorithm can consider whether the centroid of the best correlated templates as an initial solution, weighted with the cross correlation using a normalized coefficient, or just the location of the template with the maximum NCCC.

Furthermore, different quality controls has to be applied during the iterative process. First, a residual control is applied. After the first iteration, all the residuals of all the equations introduced to our system are evaluated. If these time residuals are higher than a time threshold, this equations are subtracted from the system. If the remaining number of equations are under 5 , the subtraction is cancelled and the iteration continues. Second, if the spatial corrections are above certain distance threshold, the iteration stops and tries to find the corrections using an alternative initial location. Finally, if the minimization raises an r-squared value higher than 0.999 , the iteration is finished and the new location is stored. Otherwise, if the system does not converge or after a certain number of iterations, the workflow finishes. 


\subsection{Parallelization and Data Storage}

Within our methodology we have sectioned each part as independent modules. We consider the possibility that in the future different more sophisticated algorithms may be incorporated for detection, phase picking or localization, therefore, we have proposed the code so that each module can be used separately.

We took advantage of the modular structure proposed to code and parallelize the analysis of seismic swarms in the simplest and most optimal way. For this purpose, we have separated the parallelization into two blocks: On the one hand, detection and on the other hand, phase picking and localization.

Detection is performed between two timestamps in all the selected stations. Therefore, the parallelization could be performed between multiple pairs of timestamps (in our case, hours) at the same time. Moreover, once the detections are obtained, phase picking and localization are performed. Since our methodology analyzes each event independently, we can classify the parallelization of the process as "embarrassing parallel" where in each CPU thread the analysis, phase picking localization and relocalization, are performed.

For each event, an individual JSON file is generated including the obtained phases (Robust and/or Fine), the time differentials of the cross-correlation and the cross-correlation coefficient. In addition, a text file is generated where the hypocentral parameters and the origin time obtained by Hypoellipse and by the Master-Cluster method are stored with the corresponding errors.

\section{DATA}

Two data sets have been used to test the methodology described. These data sets correspond to a couple of dense seismic swarms monitored by Instituto Geografico Nacional, Spain (1999), (IGN). In both cases there is a lack of low magnitude events in the catalog. Its known that the manual analysis of these series left behind a large number of earthquakes and the automatic processes which dealt with the data on real time had been overload. That were not analysed for various reasons, such as the difficulty of identifying phases and the impossibility to manually analyze all data during dense periods of the seismic series. 
Table 1. Ground velocity model used for El Hierro and Torreperogil seismic series.

\begin{tabular}{cccccc}
\hline \multicolumn{3}{c}{ El Hierro } & \multicolumn{4}{c}{ Torreperogil } \\
\hline $\begin{array}{c}\text { Depth } \\
{[\mathrm{km}]}\end{array}$ & $\mathrm{Vp}[\mathrm{km} / \mathrm{s}]$ & $\mathrm{Vp} / \mathrm{Vs}$ & $\begin{array}{c}\text { Depth } \\
{[\mathrm{km}]}\end{array}$ & $\mathrm{Vp}[\mathrm{km} / \mathrm{s}]$ & $\mathrm{Vp} / \mathrm{Vs}$ \\
\hline 0 & 4.2 & 1.78 & 0 & 6.1 & 1.75 \\
4 & 6.3 & 1.78 & 11 & 6.4 & 1.75 \\
12 & 7 & 1.78 & 24 & 6.9 & 1.75 \\
18 & 8 & 1.78 & 31 & 8 & 1.75 \\
\hline
\end{tabular}

The first data set includes the seismic series that preceded the submarine eruption of Tagoro Volcano in the South of El Hierro (Figure 1 1a), Canary Islands, Spain. The series started on $19^{\text {th }}$ of July 2011 in the center of the island and migrated southern towards the sea where the eruptive vent opened on the $10^{\text {th }}$ of October 2011 (López et al. 2012; Domínguez Cerdeña et al. 2014; SainzMaza Aparicio et al. 2014; Meletlidis et al.2015). This spatial evolution of the seismicity (Fig. 1) is of great interest to test the designed algorithm. For the analysis, we have used all the seismic stations of the IGN network on the island (Fig. 11d). An extensive description of the evolution and succesive deployment of the seismic network (Fig. 1 $1 \mathrm{~b}$ ) can be found in the literature (López et al. 2012; Domínguez Cerdeña et al. 2014).

On the other hand, we have chosen another series occurred in the South of the Iberian Peninsula with a purely tectonic origin, the Torreperogil seismic swarm (Fig. 2a). The activity started on $10^{\text {th }}$ of October 2012 and lasted for 6 months till the $25^{\text {th }}$ of April 2013 (Fig. 2r). We have used data from stations of the IGN network in the analysis (Fig. 2 and d). As in the previous data set, the seismic network where not very dense at the beginning of the series (Fig. 1 $\mathrm{b}$ ), however, four more stations were deployed by late November when seismicity started to increase. A detailed analysis of the characteristics of this series can be found in Cantavella et al. (2013).

As long as the IGN catalog locations have been obtained with a different algorithm (Locsat), we have considered its manually picked arrivals and relocated the events using Hypoellipse in order to make them comparable with the solutions of our methodology for both datasets, El Hierro (Fig.1F) and Torreperogil (Fig.2). To ensure homogeneity and to be able to compare the results of 

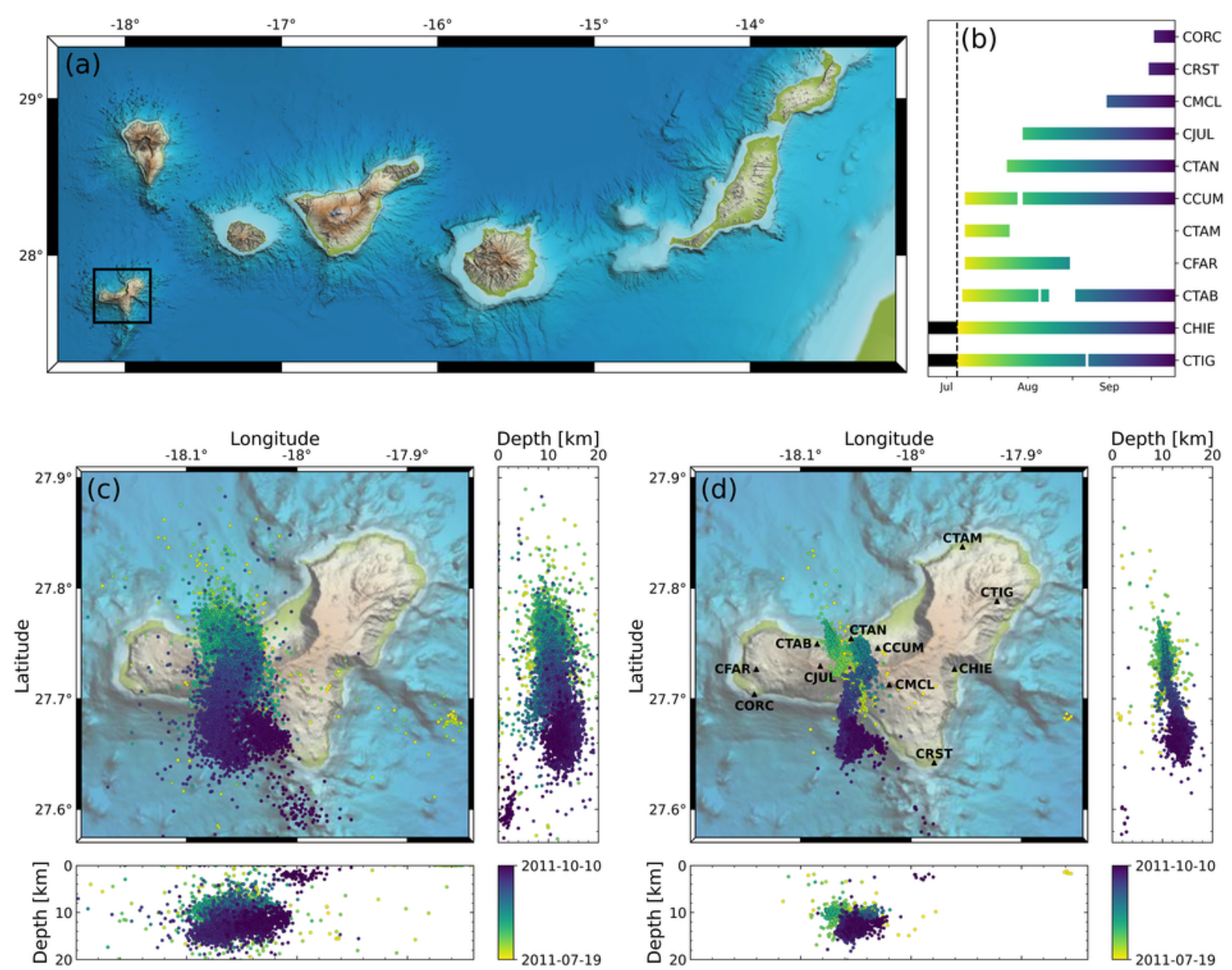

Figure 1. Pre-eruptive seismicity of El Hierro eruption (2011). (a) Location of El Hierro highlighted in the Canary Island Archipelago. (b) Evolution of the seismic network indicating the periods of working time for each station. (c) Seismicity of the IGN catalog located by Hypoellipse. Panels show horizontal distribution and vertical projections in latitude and longitude. (d) Seismic templates $(\mathrm{m} \geq 1.5)$ relocated by HypoDD and local seismic network distribution. The color distribution indicates the time evolution, from $19^{\text {th }}$ of July (yellow) to $10^{\text {th }}$ of October (dark purple).

the program between both data sets, we have used the same criteria to select the templates. Previous studies have evaluated the completeness magnitude of the IGN catalog for both swarms, obtaining

et al. 2017) for Torreperogil. Accordingly to this values, we have selected as templates those earthquakes from both catalogs that have a magnitude equal to or greater than $1.5 \mathrm{mbLg}$. In the El Hierro catalog, there are a total of 3601 out of 10000 earthquakes that satisfy this criterion. For Torreperogil, of the 2500 earthquakes in the seismic catalog, a total of 796 earthquakes fulfill this 

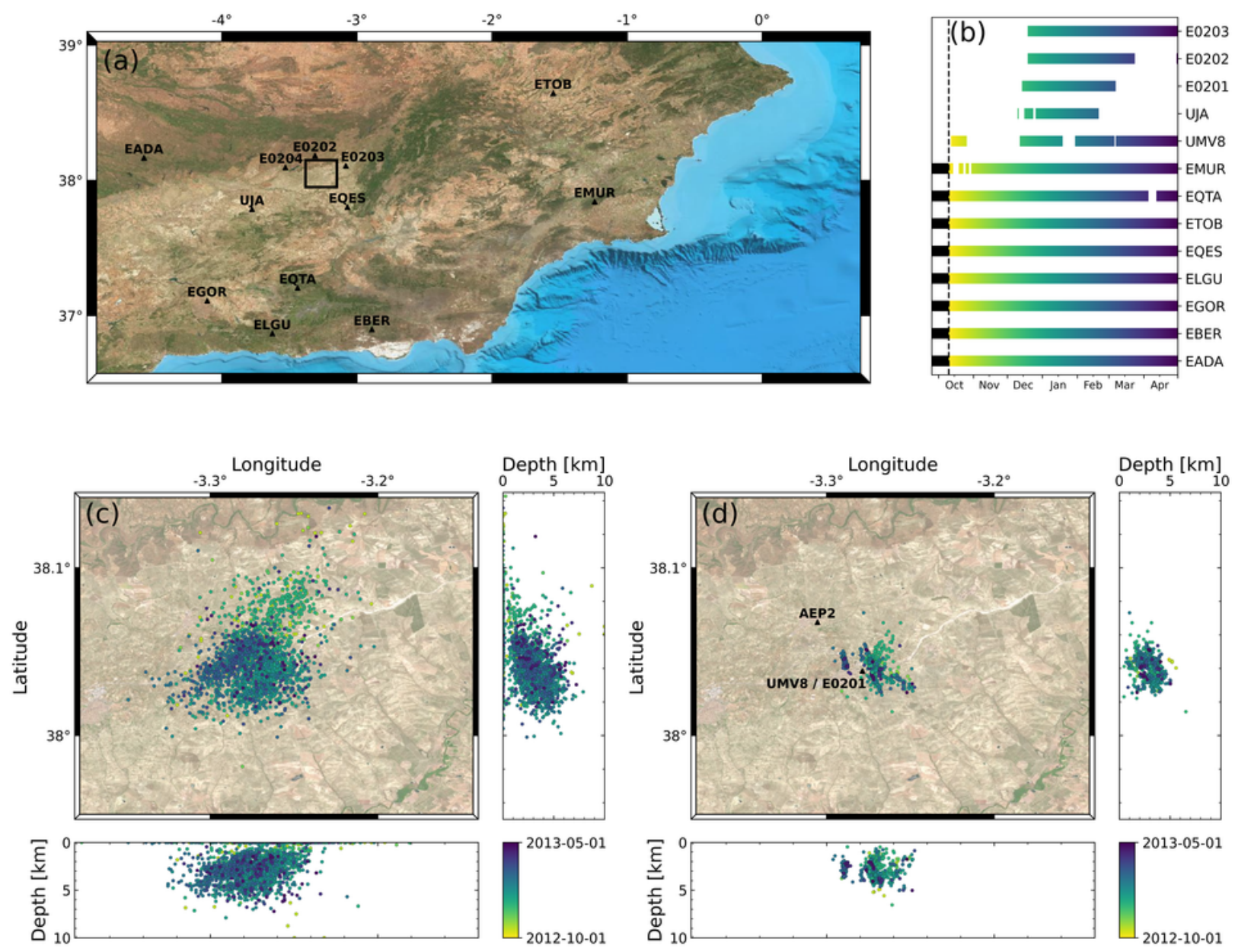

2012-10-01

Figure 2. Torreperogil seismic swarm 2012-2013. (a) Torreperogil location on the south of the Iberian Peninsula and the seismic network. The black square highlight the Torreperogil area used from now in future maps. (b) Evolution of the seismic network indicating the periods of working time for each station. (c) Seismicity of the IGN catalog located by Hypoellipse. Panels show horizontal distribution and vertical projections in latitude and longitude. (d) Seismic templates $(\mathrm{m} \geq 1.5)$ relocated by HypoDD and local seismic network distribution. The color distribution indicates the time evolution, from $1^{\text {st }}$ of October of 2012 (yellow) to $1^{\text {st }}$ of May of 2013 (dark purple).

criterion. Both template set have been relocalized using HypoDD (Fig. 1 d, Fig. 2d) and considering the velocity models (Table 1) .

Though both seismic swarms have been widely studied due to their geological and geodynamical interest (Meletlidis et al. 2015; Sainz-Maza Aparicio et al. 2014; Sánchez-Gómez et al. 2014; Peláez et al. 2013; Pedrera et al. 2013), a further analysis on the continuous waveform in order to detect and locate microseismicity and enhance the seismic catalog has not been done yet. 


\section{APPLICATION SETTINGS AND RESULTS}

Although the algorithms has been developed for automatic operation, certain parameters need to be adjusted and calibrated in order to obtain optimal results. In this section we present the parameters used for the analysis of the two test data sets and the results obtained.

\subsection{El Hierro}

The detector has been calibrated using thoroughly manually revised hours. These intervals correspond to three different states of the activity: an hour without earthquakes, a noisy hour with some earthquakes and an hour with more than a hundred earthquakes. The best performance have been obtained for a $3 \mathrm{~s}$ of STA window, $11 \mathrm{~s}$ for LTA window, a trigger ratio of 2.7 and a bandpass butter-worth filter between 6 and $16 \mathrm{~Hz}$. Values obtained for $R$ and $F_{1}$, Eq. 2 and 3 , are a $R=0.77$ and $F_{1}=0.88$ respectively. This detection parameters were selected after testing the detector to a set manually revised hours of the swarm and obtaining an $R=0.79$ and $F_{1}=0.89$, which corroborate the calibration reliability.

The resulting number of detections as potential earthquakes was 40330 . Figure 3 a, shows the evolution of number of earthquakes per day detected by our method (pink bars) and the 10010 earthquakes registered in the IGN catalog (gray line). Both records show similar trends at the beginning of the crisis but an outstanding difference between them in late July and during the days before the eruption onset (October $10^{\text {th }}$ ).

Each detection has been analyzed by applying the phase picking method described in Sec. 2.2 . The seismic stations used for this swarm are located at similar distances from the hypocenters in a regional configuration, therefore, differences between $\mathrm{P}$-wave and $\mathrm{S}$-wave arrivals are similar for each station, approximately 2 seconds. Assuming this, we have segmented the templates of all the stations using the same time length: 2 seconds before the P-wave arrival and 5 seconds after. If the 

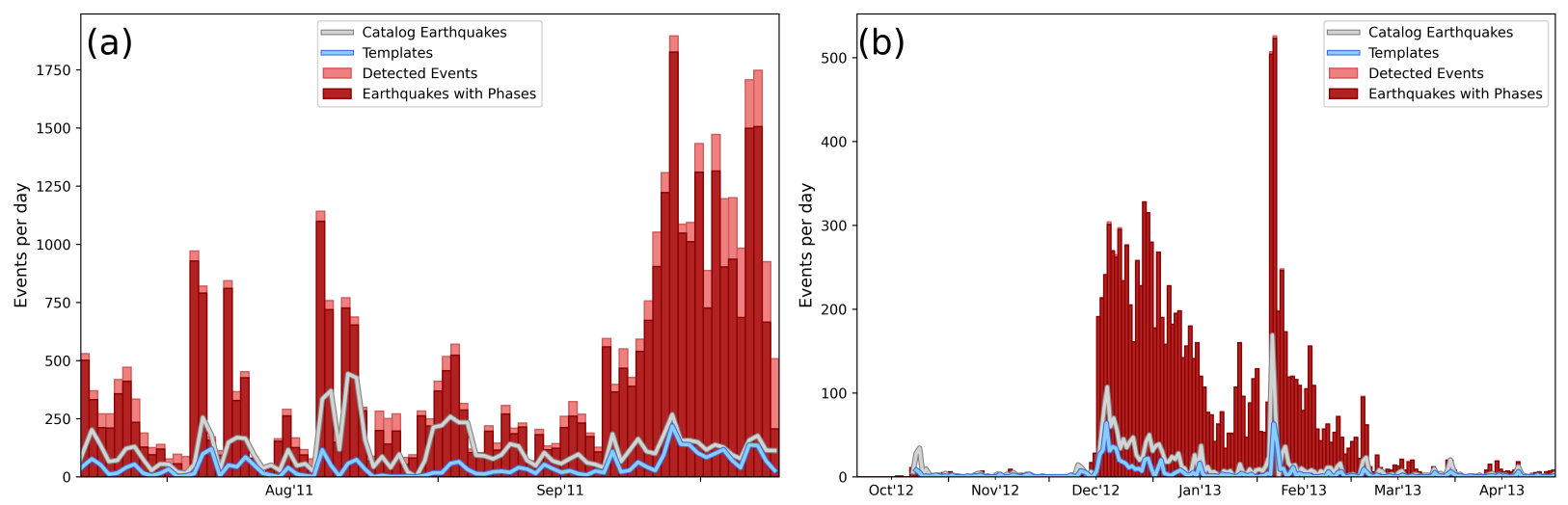

Figure 3. Evolution of the number of the events comparing the results automatically obtained (bars) with manual analysis (lines) for El Hierro (a) and Torreperogil (b). The pink bars represents the total number of detected events by our algorithm. Red bars represents the number of confirmed earthquakes detected. Gray line is the number of earthquakes in the IGN catalog and the blue line is the number of templates selected for our study

P-wave was not picked in the template, segmentation is done 5 seconds before the S-wave and 2 seconds after.

Furthermore, detections have been segmented in a 20 seconds windows, at each station: 5 seconds before detection and 15 seconds after. We have selected this time length to prevent possible errors in the detection time. These lack of accuracy can result due to the energy calculation is averaged over 1 second windows overlapping 0.5 seconds, so that the temporal precision decreases.

Templates have been cross correlated over the detection windows. Those with a NCCC $\geq 0.7$ have been used to obtain the $\mathrm{P}$ and $\mathrm{S}$ Robust Phases. Then, we proceeded with the Fine Phases calculation, for those stations where we had successfully obtained Robust Phases. The time windows selected to determine the Fine Phase picking are: For templates, the $\mathrm{P}$ waves were segmented 1 second before and after the arrival and the S-wave, were segmented 1.5 seconds before and 1 second after. Moreover, the traces with Robust Phases were segmented as it follows: 1 second before the P Robust Phase and 1.5 seconds after and 1 second before the S Robust Phase and 2.5 seconds after. These phases are cross correlated with the templates and those that obtain a NCCC $\geq 0.8$ are used to calculate the Fine Phases.

After the phase picking step, we have confirmed as real earthquakes 35040 detections which had, at least, a single successful correlation in one station (Figure 3 a, red bars). The number of 

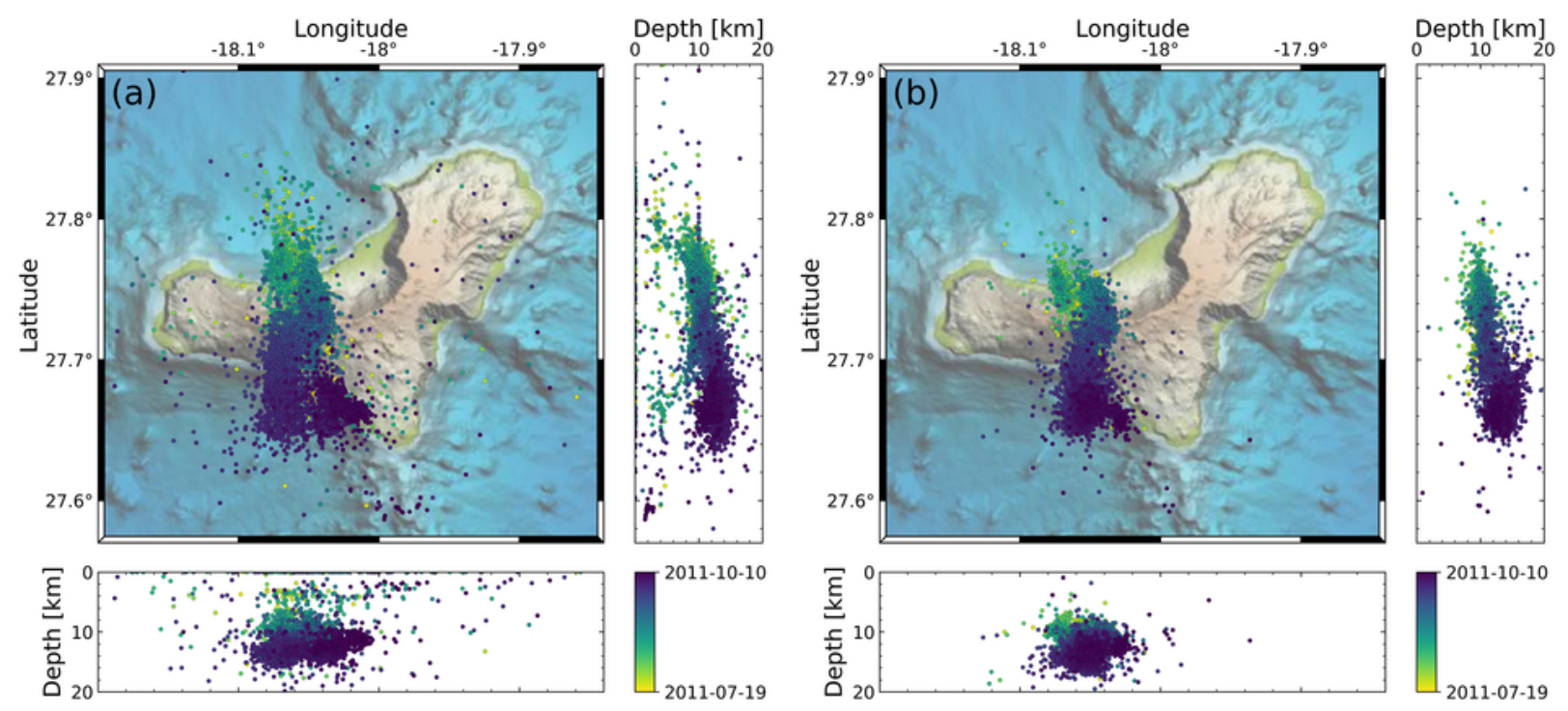

Figure 4. New seismic catalog for El Hierro: (a) Hypoellipse solutions. Panels show horizontal distribution and vertical projections in latitude and longitude. (b) Master-Cluster solutions. The color distribution indicates the time evolution, from $19^{\text {th }}$ of July (yellow) to $10^{\text {th }}$ of October (dark purple)

earthquakes confirmed in three or more stations is 29836 , which corresponds to the $85 \%$ of the confirmed events. Comparing the number of phases obtained by phase picking and the manually picked phases in the IGN catalog, our algorithm obtains $174440 \mathrm{P}$ phases and $174780 \mathrm{~S}$ phases versus the $22423 \mathrm{P}$ phases and $22919 \mathrm{~S}$ phases of the IGN catalog, which means an increase in a factor of 7.6 in the number of seismic phases. Moreover, phase classification has been settled in terms of the phase quality (Sec. 2.2), separating the best quality phases (Fine Phases) from the rest of the others (Robust Phases). When applying the cross-correlation method, the $30 \%$ of the P arrivals and the $80 \%$ of the S arrivals were classified as Fine Phases.

Earthquakes with phases in three or more stations have been located with Hypoellipse (Fig. 4 a). The resulting hypocentral locations obtained with our algorithm follow the same spatial distribution as in the IGN catalog (Fig. 17). The increase with respect to the number of templates used was a factor 8.2 , while this factor is 2.9 with respect to the complete IGN catalog (Table 2).

Table 2 summarizes the results obtained for this seismic swarm. The $82 \%$ of the templates used for the phase picking have been correctly retrieved and located using the phases obtained automatically. Moreover, the $66 \%$ of the earthquakes from the IGN catalog which were non-used 
as templates (magnitude mbLg $<1.5$ ) have also been extracted from the continuous waveform and has been located.

In the other hand, the events have been located by means of the Master-Cluster method, as defined in Eq. 7, combined with the bootstrap method. The number of earthquakes located by Master-Cluster method ascends to 21086 , which is an increment in a factor 2.1 larger than the IGN catalog and a factor 5.9 larger than the number of earthquakes used as templates. MasterCluster solutions (Fig. $4 \mathrm{~b}$ ) define a more constrained and better defined structure than the previous IGN catalog (Figure 1c). As it was expected, this results are more similar to those obtained by HypoDD (Figure 1d).

In order to have a good approximation of the error intervals associated to our solutions, the bootstrap method has been applied. Using the time residuals from Eq. 7 we have resampled 100 times the solution. Subsequently, each coordinate is taken as the median value of the resampling and the error is estimated as the robust median of the resampling set. The latitude, longitude and depth median for Master-Cluster are 121, 60, 93 meters, which are much lower in respect to Hypoellipse errors 420, 1080, 860 meters.

\subsection{Torreperogil}

For the seismic swarm of Torreperogil, the analysis has followed the same schedule as in the previous dataset. The detector have been calibrated using three hours of data: the first two hours to obtain the optimal parameter combinations and a third one to test the resulting parameter combination. The reference hours showed value of $R=0.62$ and $F_{1}=0.77$ and the test hour showed a $R=0.69$ and $F_{1}=0.81$. The best parameter combination for our detector in this seismic swarm uses a $6-13 \mathrm{~Hz}$ bandpass filter, 5 and $16 \mathrm{~s}$ for STA and LTA time window respectively and a 2.6 threshold to trigger the detector, and leads to a result of 12006 potential events (pink bar in Fig. 3b). During the same period, $20^{\text {th }}$ October 2012 and $1^{\text {st }}$ May 2013, the IGN catalog includes 2100 earthquakes registered in the same area (grey line in Fig. 3b).

The seismic network used in Torreperogil crisis covers from local distances $(4-50 \mathrm{~km})$ to regional distances $(80-140 \mathrm{~km})$, (Fig. 2a, 2d). Therefore, we have adapted the template time lengths 

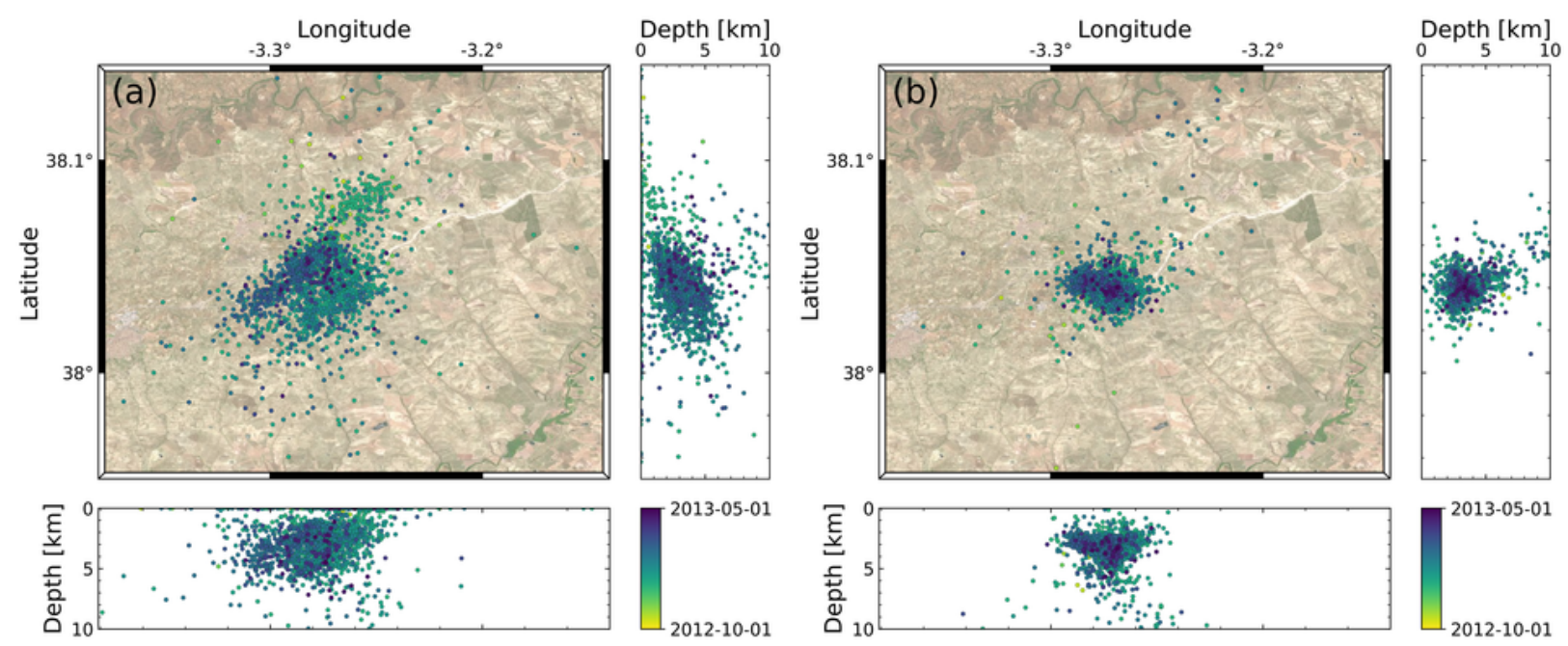

Figure 5. New seismic catalog for Torreperogil: (a) Hypoellipse solutions. Panels show horizontal distribution and vertical projections in latitude and longitude. (b) Master-Cluster solutions. Color distribution indicate the time evolution, from $1^{\text {st }}$ of October of 2012 (yellow) to $1^{\text {st }}$ of May of 2013 (dark purple).

to each station. These lengths were segmented from 3 seconds before $\mathrm{P}$ wave arrival to $t_{s}-t_{p}+3$ seconds after the $\mathrm{P}$ wave arrival. If there is no $\mathrm{P}$ wave picked, templates were segmented from $t_{s}-t_{p}-3$ seconds before the $\mathrm{S}$ arrival and 5 seconds after.

For local stations $(4-50 \mathrm{~km})$, the Robust Phase picking is calculated by a full wave cross correlation around the detection time, 5 seconds before the detection and 15 seconds afterwards. Subsequently, the Fine Phase picking was developed as it was introduced in Sec. 2.2. P wave templates were segmented from 1 second before to 1 second after the time arrival and the $S$ wave from 1 second before to 2 seconds after the $S$-wave arrival. The detected events were cropped 1 second before the P Robust Phase and 1.5 seconds after, and S Robust Phase from 1 second before to 2.5 seconds after.

For regional stations $(80-140 \mathrm{~km})$, we have extracted from the templates the $\mathrm{P}$ and $\mathrm{S}$ waves and correlated them around the theoretical arrivals. At each station, the time window lengths to correlate the templates with the detections depend on the time difference between the $\mathrm{P}$ and $\mathrm{S}$ wave arrival. This dependence with $t_{S}-t_{P}$ has been introduced to take into account the possible error made in theoretical phase arrival determination. For the P-wave this window had a length of 
$1 / 3\left(t_{S}-t_{P}\right)$ and for the $S$-wave $3 / 5\left(t_{S}-t_{P}\right)$. If Robust Phases were obtained, the Fine Phases are calculated following the same methodology as for the local stations.

The phase picking resulted a total of 11885 confirmed events (red bar in Fig. 33). From them, 11827 include detections in three or more stations and 10899 in at least 4 stations, being, respectively the $99 \%$ and $90 \%$ of the all detected earthquakes. Comparing the number of $\mathrm{P}$ and $\mathrm{S}$ waves obtained versus the template phases there has been an increment in a factor 10: From 76868 and $82807 \mathrm{P}$ and $\mathrm{S}$ waves with cross correlation, to $7792 \mathrm{P}$ and $7406 \mathrm{~S}$ template waveforms. Using a threshold of 0.7 for the cross correlation in Robust Phases and 0.8 for Fine Phases, we found that $52.1 \%$ of the $\mathrm{P}$ waves and $69.6 \%$ of the $\mathrm{S}$ waves were classified as Fine Phases.

The IGN catalog has 796 locatable earthquakes with a magnitude (mbLg) higher or equal to 1.5, which have been used as templates, and 1324 locatable earthquakes with lower magnitude. Our method have picked automatically the $92 \%$ of the templates and the $87 \%$ of the low magnitude earthquakes. Altogether, 10008 earthquakes have been successfully located applying Hypoellipse (Figure 5a) algorithm to the cross correlated phases, which means 4.7 more earthquakes than IGN catalog currently have (Figure 2k). Median errors associated to hypoellipse solutions are for latitude, longitude and depth 360, 790, 2490 meters respectively.

As in El Hierro, the Master-Cluster algorithm has been applied using bootstrapping (Figure 5b). This method has been applied, resampling the solution 100 times. As a results, the method have located 8460 earthquakes. From those, the $85 \%$ of the IGN catalog, the $86 \%$ of the templates and $85 \%$ of the non used templates $(\mathrm{mbLg}<1.5)$. This number is a factor 4 higher than the number of registered earthquakes in the IGN catalog for the same period and 10.6 times of the 796 earthquakes used as templates. Master-Cluster have median errors for latitude longitude and depth 14, 85,100 meters respectively.

\section{DISCUSSION}

The application of the proposed methodology to the seismic series of El Hierro and Torreperogil has significantly increased the number of analyzed earthquakes for both swarms. After consid- 

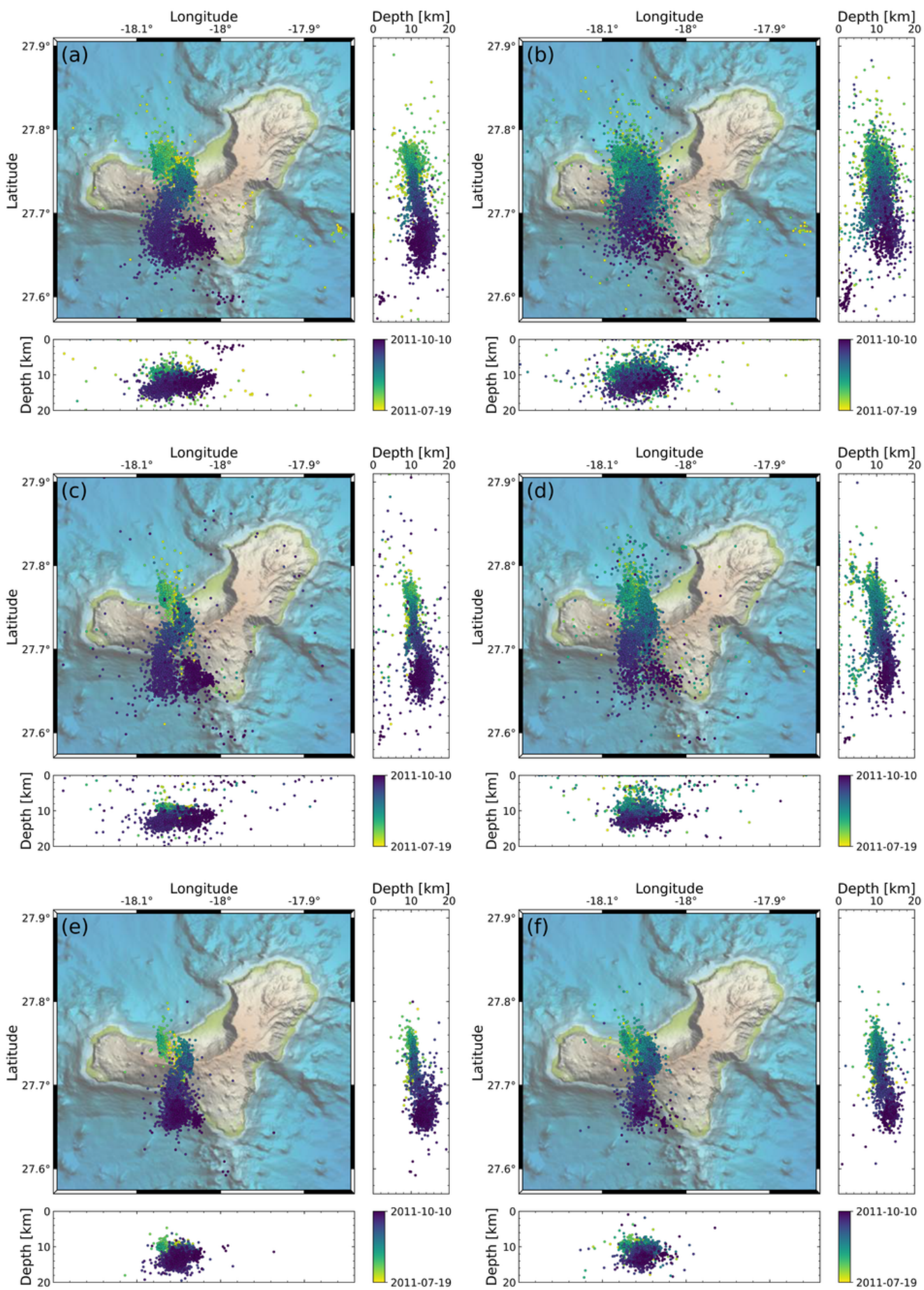

Figure 6. Results of the automatic system for the El Hierro IGN catalog events separated in templates $(\mathrm{m} \geq 1.5$; left panels) and low magnitude earthquakes not used as templates $(\mathrm{m}<1.5$; right panels). From top to bottom we show locations by Hypoellipse from manually picked phases ( $a, b)$, locations by Hypoellipse using automatic picked phases (c, d) and locations from Master-Cluster method. 

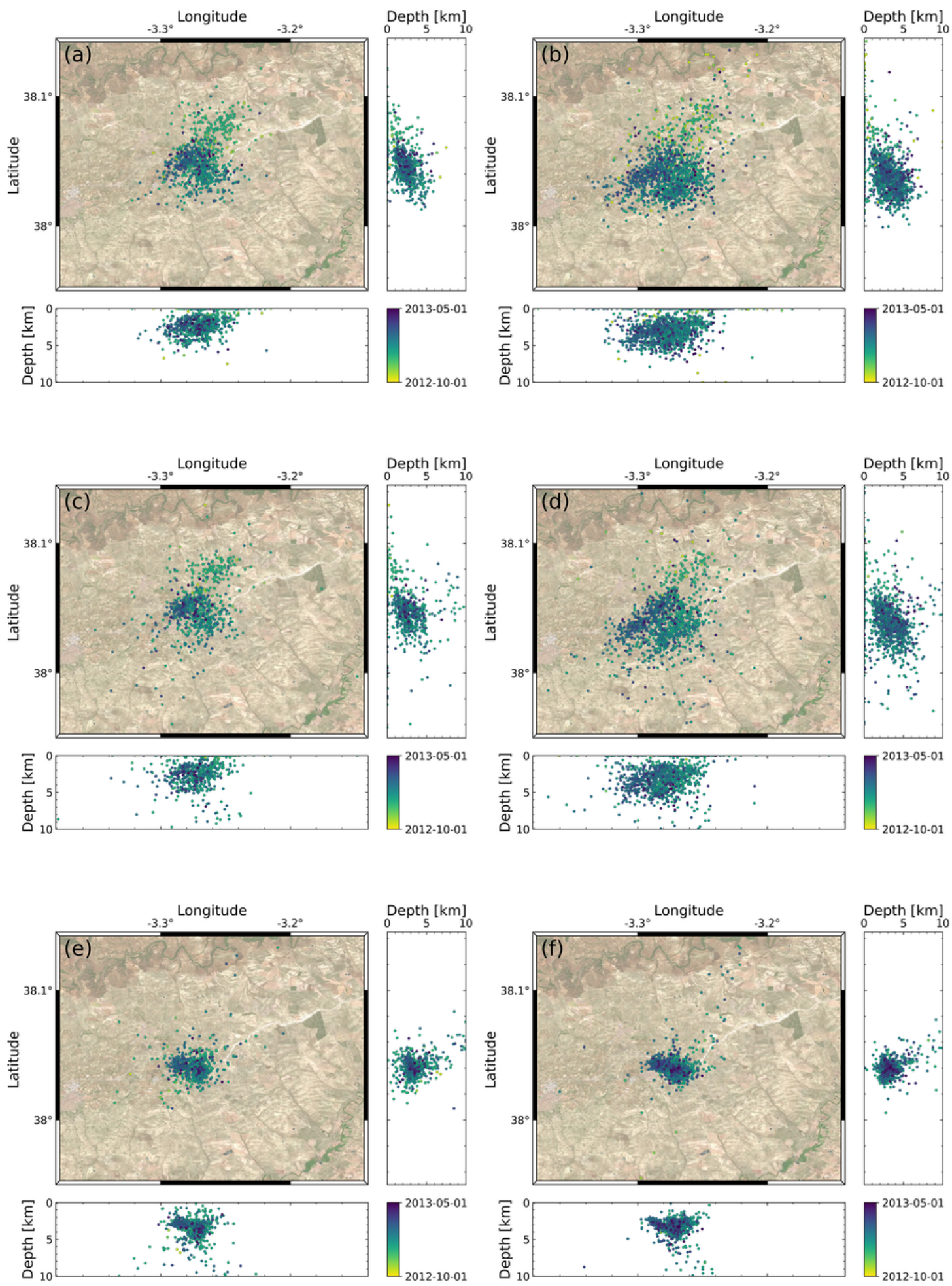

Figure 7. Results of the automatic system for the Torreperogil IGN catalog events separated in templates $(\mathrm{m} \geq 1.5$; left panels) and low magnitude earthquakes not used as templates $(\mathrm{m}<1.5$; right panels). From top to bottom we show locations by Hypoellipse from manually picked phases ( $a, b)$, locations by Hypoellipse using automatic picked phases (c, d) and locations from Master-Cluster method. 
Table 2. Number of earthquakes for different subsets including the IGN Catalog and New Catalog obtained with our algorithm for El Hierro and Torreperogil datasets. New Catalog is splitted in Detections (potential events confirmed), Locations (events from Detections located with Hypoellipse) and Master-Cluster (events relocated with Master-Cluster). Numbers are given for results on templates (IGN Catalog, $\mathrm{m} \geq 1.5$ ), lowmagnitude earthquakes from original catalog (IGN Catalog, $\mathrm{m}<1.5$ ) and events added to the new catalog (New Events)

\begin{tabular}{llcccc}
\hline \multirow{2}{*}{ Data Set } & IGN Catalog & \multicolumn{3}{c}{ New Catalog } \\
\hline \multirow{3}{*}{ El Hierro } & Classification & & Detections & Locations & Master-Cluster \\
\cline { 2 - 5 } & IGN Catalog $(\mathrm{m} \geq 1.5)$ & 3601 & 2939 & 2936 & 2930 \\
& IGN Catalog $(\mathrm{m}<1.5)$ & 6377 & 4223 & 4214 & 3999 \\
& New Events & - & 28138 & 19601 & 14157 \\
\cline { 2 - 6 } Torreperogil & Total & 9978 & 35300 & 26751 & 21086 \\
\cline { 2 - 6 } & IGN Catalog $(\mathrm{m} \geq 1.5)$ & 796 & 752 & 733 & 687 \\
& New Events & 1324 & 1170 & 1159 & 1123 \\
\cline { 2 - 6 } & Total & - & 9880 & 8116 & 6650 \\
\hline
\end{tabular}

ering 3601 templates for El Hierro and 796 for Torreperogil, the resulting number of potential earthquakes is at least a factor 11 higher than the number of templates.

The cross-correlation phase picking has allowed us to discriminate between earthquakes and false positive detections. In both datasets, the difference between real earthquakes in at least one station and false detections is not very significant: in El Hierro 13\% of the detections are false positives and $2 \%$ in Torreperogil. Hence, we consider the calibrations of the detector good enough for the automatic algorithm to work without further supervision.

We have assumed that the templates we have selected from the seismic catalog are representative of the activity and reflect all the possible families of earthquakes in these series. Otherwise, it remains the possibility that some of the events we have labelled as false positives are earthquakes for which there is no template in our catalogues. This situation would be more likely to occur in the case of El Hierro crisis, where the waveform of the families is evolving since the seismicity was associated with magma migration and a larger number of families are involved (Domínguez Cerdeña et al. 2014). For this case, a manual review has been made in case it was a systematic error or a 


\section{4}

EAD Suarez et al.

family of earthquakes for which there was no record in the selected templates. We have found that mostly, the earthquakes that fail to be analyzed are at the end of the series (Fig. 3a). Nevertheless, the apparent false detections are a small percentage of the total events. These numbers are reasonable ratios, considering the variability of the seismic network (Figs. $2 \mathrm{p} 1 \mathrm{p}$ ), the earthquakes with a low signal to noise ratio and the limitations of the method itself, especially during the first period of the swarms when a low number of stations were available.

Locations obtained by applying Hypoellipse (Fig. 4 a and Fig. 5b) are consistent with the previous locations obtained by manual analysis (Fig. 1k and Fig 2k) in both data sets. These solutions are consistent with the results shown in previous works (Cantavella et al. 2013; Domínguez Cerdeña et al. 2014) with similar epicentral distributions, but with larger scatter. This apparent low quality of the locations is produced by the large number of earthquakes with lower magnitude picked automatically.

The Master-Cluster event methodology shows a substantial improvement of the earthquake locations in El Hierro (Fig. $4 \mathrm{~b}$ ), despite decreasing the number of converging earthquakes by $26 \%$ with respect to those located with Hypoellipse (Fig. 4a). In the case of Torreperogil, the earthquakes located by Hypoellipse show a similar distribution (Fig. 5a) as the original IGN catalog (Fig. 2r) while the Master-Cluster method shows an important improvement in the hypocentral location (Fig. 5b), but with larger dispersion than El Hierro solutions. This difference is probably related to the different path of the traces, the scenario of El Hierro deals with rays coming from a source at $12 \mathrm{~km}$ depth recorded at local stations, most of the rays arrive almost vertically in the stations and show in most of the cases impulsive $\mathrm{P}$ and $\mathrm{S}$ arrivals. In Torreperogil, sources are shallower and some of the stations used are placed at regional scales, more refracted and reflected waves are produced in the upper crust and also rays are more likely to be affected by other phenomena as scattering. In consequence, seismic phases are more emergent and more difficult to be identified. Also, the assignment of phases to an event may be poorly done for stations at large distances due to the large width of windows chosen for phase picking by cross-correlation. Additionally, the filters used for cross-correlation at stations at local distances respect to the regional ones are not optimal for the identification of seismic phases. Finally, the velocity model used for 
both datasets may increase the uncertainties in the location since it may not be the optimal for these areas, especially for stations at local distances, as they may have a worse determination of the hypocentre. However, for this work, we have not discussed the ground velocity models applicable to both areas. Despite the existence of a local velocity model for Torreperogil (Serrano et al. 2015 ) it was impossible to apply it with regional and local stations at the same time. There is also a 3D model for El Hierro island (García-Yeguas et al.2014), however, the model is not published and it is not possible to apply it to HypoDD or Hypoellipse algorithm. Therefore, we have used the IGN generic velocity model for the whole Iberian Peninsula or the Canary Islands. A more detailed ground model for the stations at local distances can give a more detailed model for the local distances. Consequently, the possibility of studying the influence of the different earth models on the location of the series remains open.

In order to perform a proper analysis of the capabilities of the method, we have carefully analyzed the results obtained only for IGN catalog events, including low magnitude earthquakes $(\mathrm{mbLg}<1.5)$ not used as templates (Figs. 6, 7). In both cases most of the earthquakes were automatically located even improving the result from the manual catalog. For the case of El Hierro, there is a substantial improvement in the locations obtained with Hypoellipse by our automatic methodology (Fig. 6d), with respect to the manually analyzed seismicity (Fig. 6b). This is a consequence of manual picking for low magnitude earthquakes, usually biased due to the low signalto-noise ratio, implying higher residuals due to the difficult to clearly identify the arrival of the seismic phases. This result is the most remarkable when it comes to possible implementation in real-time systems since these earthquakes are usually the most difficult to manually analyze.

For the case of Torreperogil we found similar Hypoellipse locations for the low magnitude seismicity manually (Fig. 7p) or automatically picked (Fig. 7d). Despite there is not an improvement in the locations the number of automatic analyzed earthquakes is indeed a major advance. The comparison described above for both swarms is independent of the availability of relocated templates which may take advantage of reanalyzed events that may not be accessible to the automatic method in case of a real time application of the method. For both cases there is a clear improvement in the locations when we compare manually picked earthquakes with those obtained 
by the Master-Cluster method (Figs $6 \mathrm{f}$ and 7f) with almost no loss on number of events due to missconvergence (Table 2).

A further test on our methodology is its capability to recover automatically the templates with the better possible quality. The results are in both cases very similar as for the low magnitude events. In the case of El Hierro there is an important improvement between manually picked (Fig. 6a) and automatically (Fig. 66) located events with Hypoellipse. The Master-Cluster result (Fig. 6e) is remarkable with a similar result as the actual relocated events (Fig. 11d). In the case of Torreperogil the result is very similar for manually picked (Fig. $7 \mathrm{a}$ ) and automatically (Fig. $7 \mathrm{~F}$ ) located events with Hypoellipse. The distribution of the seimsicity obtained with Master-Cluster (Fig. 77) shows much more clustering than the manually picked but is not as good result as that obtained directly by relocation (Fig. $2 \mathrm{~d}$ ).

In El Hierro, the phase picking and localization consumes a total of 20 seconds per event, while it was 12 seconds for Torreperogil events. The average detection time per hour is 10 seconds for both crises. Using an Intel (R) core (TM) i7-8700 CPU $3.200 \mathrm{GHz}, 6$ cores-12 threads, the total elapsed time for El Hierro, 3 months of data in 11 stations have been 84.6 hours, while, in Torreperogil, 13 stations with 7 months of data the computer spent 61.2 hours. This time difference is explained by the difference in the number of earthquakes detected during the seismic crises. Therefore, the automatic method seems to reliably reproduce the manual analysis in a considerably shorter time.

\section{CONCLUSIONS}

We have implemented an automatic detection and location method for seismic swarms that improves the results of manual analysis and can save a large amount of time in any seismological observatory. In addition to improved catalog localization, the resulting catalog is greatly expanded, which can improve the completeness of the seismic catalog. This is essential to provide more detailed information on processes, whether they are purely tectonic seismic series or those related to volcanic activity, which can produce a substantial improvement in the forecast of volcanic eruptions. This work also presents a new technique for relocalization, Master-Cluster, which takes 
advantage of two well known techniques, the master event and the double differences. This technique may be used in our automatic system to enhance the seismic catalogs, especially when a relocated catalog is available.

By using a small number of earthquakes as characteristic templates of both swarms, we have extended the number of earthquakes analysed with short computation times. In El Hierro, with 3601 relocalized and manually picked templates, more than 35000 earthquakes have been confirmed and more than 27000 earthquakes have been located with Hypoellipse and 22000 with the Master-Cluster method. In Torreperogil, with 796 relocalized and manually picked templates, more than 11800 earthquakes have been confirmed, of which almost 10000 have been located by Hypoellipse and approximately 8000 by the Master-Cluster method. Both results show less scatter in the hypocentral distributions and are able to reproduce more accurately the catalogue earthquakes that have not been used as templates.

Despite is not a purely automatic system, it is still to be analyze the needed number of templates to produce a substantial improvement. Moreover, since the templates are the larger earthquakes (in our work $\mathrm{m} \geq 1.5$ ) this template catalog can be obtained by other automatic methodologies which may work well by high SNR events. The only use of the automatic phases obtained from the correlation with templates of the original seismic catalog has given an improved new catalog with similar or even better location. This fact has been proved by the tests performed with the low magnitude events from the original catalog. The application of the Master-Cluster method to these results improves substantially the hypocentral locations thanks to the use of a better relocated catalog of templates. However, this is not essential to be used in an hypothetical real time automatic system, and can be applied at any post-process analysis when a relocated catalog of templates is available.

\section{ACKNOWLEDGMENTS}

The authors would like to thank Jaime Barco, Resurrección Antón and Juan Vicente Cantavella for their comments, clarifications and access to the Torreperogil crisis data (2012-2013). They would also like to thank the 24-hour shift of the Spanish National Seismic Network (IGN) and the Vol- 
cano Monitoring Group (IGN) who did a titanic task in the manual analysis of the earthquakes preceding El Hierro eruption (2011). This research was partially supported by the Spanish National Geographic Institute of the Spanish Ministry of Transport, Mobility and Urban Agenda and through project CGL2014-53044-R of the Spanish Ministry of Economy and Competitiveness.

\section{DATA AVAILABILITY}

The data used in this article have been obtained from the continuous recording network of seismic stations of the Spanish National Geographic Institute. The seismic data belong to the IGN and can be accessed by request. The catalogues used can be exploited from the IGN's website (https: //www.ign.es/web/ign/portal).

\section{REFERENCES}

Allen, R., 1982. Automatic phase pickers: Their present use and future prospects, Bulletin of the Seismological Society of America, 72(6B), S225-S242.

Baer, M. \& Kradolfer, U., 1987. An automatic phase picker for local and teleseismic events, Bulletin of the Seismological Society of America, 77(4), 1437-1445.

Beaucé, E., Frank, W. B., \& Romanenko, A., 2017. Fast Matched Filter (FMF): An Efficient Seismic Matched-Filter Search for Both CPU and GPU Architectures, Seismological Research Letters, 89(1), $165-172$.

Bent, A. L., Cassidy, J., Prépetit, C., Lamontagne, M., \& Ulysse, S., 2018. Real-Time Seismic Monitoring in Haiti and Some Applications, Seismological Research Letters, 89(2A), 407-415.

Benz, H., 2017. Building a National Seismic Monitoring Center: NEIC from 2000 to the Present, Seismological Research Letters, 88(2A), 265-269.

Beyreuther, M., Barsch, R., Krischer, L., Megies, T., Behr, Y., \& Wassermann, J., 2010. ObsPy: A Python Toolbox for Seismology, Seismological Research Letters, 81(3), 530-533.

Bianchi, M. B., Assumpção, M., Rocha, M. P., Carvalho, J. M., Azevedo, P. A., Fontes, S. L., Dias, F. L., Ferreira, J. M., Nascimento, A. F., Ferreira, M. V., \& Costa, I. S. L., 2018. The Brazilian Seismographic Network (RSBR): Improving Seismic Monitoring in Brazil, Seismological Research Letters, 89(2A), $452-457$.

Cantavella, J., Morales, J., \& Martinez-Solares, J., 2013. La serie sísmica de la comarca de La Loma (Jaén). Antecedentes, distribución temporal, localización y mecanismo focal, Jaen. Informe del grupo de 
trabajo interinstitucional sobre la actividad sísmica en la comarca de la loma (Jaen), Tech. rep., Ministerio de Fomento, Madrid.

Carmona, E., Almendros, J., Peña, J. A., \& Ibáñez, J. M., 2010. Characterization of fracture systems using precise array locations of earthquake multiplets: An example at deception island volcano, antarctica, Journal of Geophysical Research: Solid Earth, 115(B6).

Cesca, S. \& Grigoli, F., 2015. Chapter two - full waveform seismological advances for microseismic monitoring, in Advances in Geophysics, vol. 56, pp. 169-228, ed. Dmowska, R., Elsevier.

Chamberlain, C. J., Hopp, C. J., Boese, C. M., Warren-Smith, E., Chambers, D., Chu, S. X., Michailos, K., \& Townend, J., 2017. EQcorrscan: Repeating and Near-Repeating Earthquake Detection and Analysis in Python, Seismological Research Letters, 89(1), 173-181.

Chamberlain, C. J., Townend, J., \& Gerstenberger, M. C., 2020. RT-EQcorrscan: Near-Real-Time Matched-Filtering for Rapid Development of Dense Earthquake Catalogs, Seismological Research Letters, 91(6), 3574-3584.

Domínguez Cerdeña, I., del Fresno, C., \& Rivera, L., 2011. New insight on the increasing seismicity during tenerife's 2004 volcanic reactivation, Journal of Volcanology and Geothermal Research, 206(1), $15-29$.

Domínguez Cerdeña, I., del Fresno, C., \& Gomis Moreno, A., 2014. Seismicity Patterns Prior to the 2011 El Hierro Eruption. Short Note, Bulletin of the Seismological Society of America, 104(1), 567-575.

Dondin, F. J.-Y., Lynch, L., Ramsingh, C., Ryan, G. A., Papadopoulous, I., Rueppel, D., Joseph, E. P., Latchman, J. L., Robertson, R. E. A., Nath, N., Mathura, R., Balchan, A., George, S., Juman, I., Madoo, F., Manette, G., \& Ramsingh, H., 2019. The university of the west indies-seismic research centre volcano monitoring network: Evolution since 1953 and challenges in maintaining a state-of-the-art network in a small island economy, Geosciences, $\mathbf{9 ( 2 )}$.

Efron, B., 1982. The Jackknife, the bootstrap and other resampling plans, no. 38 in Regional Conference Series in applied mathematics, Society for Industrial and applied mathematics, Philadelphia, Pa.

García-Yeguas, A., Ibáñez, J. M., Koulakov, I., Jakovlev, A., Romero-Ruiz, M. C., \& Prudencio, J., 2014. Seismic tomography model reveals mantle magma sources of recent volcanic activity at El Hierro Island (Canary Islands, Spain), Geophysical Journal International, 199(3), 1739-1750.

González, Á., 2017. The spanish national earthquake catalogue: Evolution, precision and completeness, Journal of Seismology, 21(3), 435-471.

Got, J.-L., Fréchet, J., \& Klein, F. W., 1994. Deep fault plane geometry inferred from multiplet relative relocation beneath the south flank of kilauea, Journal of Geophysical Research: Solid Earth, 99(B8), 15375-15386.

Grigoli, F., Cesca, S., Priolo, E., Rinaldi, A. P., Clinton, J. F., Stabile, T. A., Dost, B., Fernandez, M. G., Wiemer, S., \& Dahm, T., 2017. Current challenges in monitoring, discrimination, and management 
of induced seismicity related to underground industrial activities: A european perspective, Reviews of Geophysics, 55(2), 310-340.

Gutenberg, B. \& Richter, C. F., 1944. Frequency of earthquakes in California*, Bulletin of the Seismological Society of America, 34(4), 185-188.

Harris, C. R., Millman, K. J., van der Walt, S. J., Gommers, R., Virtanen, P., Cournapeau, D., Wieser, E., Taylor, J., Berg, S., Smith, N. J., Kern, R., Picus, M., Hoyer, S., van Kerkwijk, M. H., Brett, M., Haldane, A., del R'10, J. F., Wiebe, M., Peterson, P., G’erard-Marchant, P., Sheppard, K., Reddy, T., Weckesser, W., Abbasi, H., Gohlke, C., \& Oliphant, T. E., 2020. Array programming with NumPy, Nature, 585(7825), $357-362$.

Hesterberg, T., Monaghan, S., Moore, D., Clipson, A., Epstein, R., Freeman, W., \& York, C., 2005. Bootstrap methods and permutation tests, Introduction to the Practice of Statistics, 14.

Instituto Geografico Nacional, Spain, 1999. Spanish digital seismic network.

Ito, A., 1985. High resolution relative hypocenters of similar earthquakes by cross-spectral analysis method, Journal of Physics of the Earth, 33(4), 279-294.

Jourdan, D. B. \& de Weck, O. L., 2004. Layout optimization for a wireless sensor network using a multiobjective genetic algorithm, in 2004 IEEE 59th Vehicular Technology Conference. VTC 2004-Spring (IEEE Cat. No.04CH37514), vol. 5, pp. 2466-2470 Vol.5.

Journeau, C., Shapiro, N. M., Seydoux, L., Soubestre, J., Ferrazzini, V., \& Peltier, A., 2020. Detection, classification, and location of seismovolcanic signals with multi-component seismic data, example from the Piton de la Fournaise volcano (La Réunion, France), Journal of Geophysical Research : Solid Earth. Kao, H. \& Shan, S., 2007. Rapid identification of earthquake rupture plane using Source-Scanning Algorithm, Geophysical Journal International, 168(3), 1011-1020.

Kao, H. \& Shan, S.-J., 2004. The Source-Scanning Algorithm: mapping the distribution of seismic sources in time and space, Geophysical Journal International, 157(2), 589-594.

Küperkoch, L., Meier, T., Lee, J., Friederich, W., \& Working Group, E., 2010. Automated determination of p-phase arrival times at regional and local distances using higher order statistics, Geophysical Journal International, 181(2), 1159-1170.

Lahr, J., Chouet, B., Stephens, C., Power, J., \& Page, R., 1994. Earthquake classification, location, and error analysis in a volcanic environment: implications for the magmatic system of the 1989-1990 eruptions at redoubt volcano, alaska, Journal of Volcanology and Geothermal Research, 62(1), 137 - 151, The 1989-1990 Eruptions of Redoubt Volcano, Alaska.

Lahr, J. C., 1999. HYPOELLIPSE: a computer program for determining local earthquake hypocentral parameters, magnitude, and first-motion pattern, U.S. Geological Survey Open-File Report, 99(23), 119.

Leys, C., Ley, C., Klein, O., Bernard, P., \& Licata, L., 2013. Detecting outliers: Do not use standard deviation around the mean, use absolute deviation around the median, Journal of Experimental Social 
Psychology, 49(4), 764-766.

Liu, M., Zhang, M., Zhu, W., Ellsworth, W. L., \& Li, H., 2020. Rapid characterization of the july 2019 ridgecrest, california, earthquake sequence from raw seismic data using machine-learning phase picker, Geophysical Research Letters, 47(4), e2019GL086189, e2019GL086189 2019GL086189.

Lopes Pereira, R., Trindade, J., Gonçalves, F., Suresh, L., Barbosa, D., \& Vazão, T., 2014. A wireless sensor network for monitoring volcano-seismic signals, Natural Hazards and Earth System Sciences, 14(12), 3123-3142.

López, C., Blanco, M. J., Abella, R., Brenes, B., Cabrera Rodríguez, V. M., Casas, B., Domínguez Cerdeña, I., Felpeto, A., de Villalta, M. F., del Fresno, C., García, O., García-Arias, M. J., García-Cañada, L., Gomis Moreno, A., González-Alonso, E., Guzmán Pérez, J., Iribarren, I., López-Díaz, R., Luengo-Oroz, N., Meletlidis, S., Moreno, M., Moure, D., de Pablo, J. P., Rodero, C., Romero, E., Sainz-Maza, S., Sentre Domingo, M. A., Torres, P. A., Trigo, P., \& Villasante-Marcos, V., 2012. Monitoring the volcanic unrest of el hierro (canary islands) before the onset of the 2011-2012 submarine eruption, Geophysical Research Letters, 39(13).

Mammen, E., 1992. When Does Bootstrap Work?, Springer New York.

Maronna, R., 2011. Robust statistical methods, in International Encyclopedia of Statistical Science, pp. 1244-1248, Springer Berlin Heidelberg.

McKerns, M. M., Strand, L., Sullivan, T., Fang, A., \& Aivazis, M. A. G., 2012. Building a framework for predictive science.

Meletlidis, S., Roberto, A. D., Cerdeña, I. D., Pompilio, M., García-Cañada, L., Bertagnini, A., BenitoSaz, M. A., Carlo, P. D., \& Aparicio, S. S.-M., 2015. New insight into the 2011-2012 unrest and eruption of el hierro island (canary islands) based on integrated geophysical, geodetical and petrological data, Annals of Geophysics, 58(5), 0546.

Mignan, A. \& Chouliaras, G., 2014. Fifty Years of Seismic Network Performance in Greece (1964-2013): Spatiotemporal Evolution of the Completeness Magnitude, Seismological Research Letters, 85(3), 657667.

Murphy, K. P., 2012. Machine learning: a probabilistic perspective, MIT press.

Okada, H., Watanabe, H., Yamashita, H., \& Yokoyama, I., 1981. Seismological significance of the 1977-1978 eruptions and the magma intrusion process of usu volcano, hokkaido, Journal of Volcanology and Geothermal Research, 9(4), 311 - 334.

Pedrera, A., Ruiz-Constán, A., Marín-Lechado, C., Galindo-Zaldívar, J., González, A., \& Peláez, J. A., 2013. Seismic transpressive basement faults and monocline development in a foreland basin (eastern guadalquivir, se spain), Tectonics, 32(6), 1571-1586.

Peláez, J. A., Francisco J., G.-T., Mario, S.-G., Carlos, S. d. G., Fernando, P.-V., \& Jesús, H.-R., 2013. La serie sísmica de torreperogil-sabiote (jaén), Enseñanza de las Ciencias de la Tierra, 21(3), 336. 
Perol, T., Gharbi, M., \& Denolle, M., 2018. Convolutional neural network for earthquake detection and location, Science Advances, 4(2).

Sainz-Maza Aparicio, S., Arnoso Sampedro, J., Gonzalez Montesinos, F., \& Martí Molist, J., 2014. Volcanic signatures in time gravity variations during the volcanic unrest on el hierro (canary islands), Journal of Geophysical Research: Solid Earth, 119(6), 5033-5051.

Saragiotis, C. D., Hadjileontiadis, L. J., \& Panas, S. M., 2002. Pai-s/k: A robust automatic seismic p phase arrival identification scheme, IEEE Transactions on Geoscience and Remote Sensing, 40(6), 1395-1404. Senobari, N. S., Funning, G. J., Keogh, E., Zhu, Y., Yeh, C.-C. M., Zimmerman, Z., \& Mueen, A., 2019. Super-efficient cross-correlation (sec-c): A fast matched filtering code suitable for desktop computers, Seismological Research Letters, 90(1), 322-334.

Serrano, I., Torcal, F., \& Martín, J. B., 2015. "high resolution seismic imaging of an active fault in the eastern guadalquivir basin (betic cordillera, southern spain)", Tectonophysics, 660, 79-91.

Stephens, C. \& Chouet, B., 2001. Evolution of the december 14, 1989 precursory long-period event swarm at redoubt volcano, alaska, Journal of Volcanology and Geothermal Research, 109(1-3), 133-148.

Sánchez-Gómez, M., Peláez, J., Garc’ia-Tortosa, F., Valera, F., \& Sanz de Galdeano, C., 2014. La serie sísmica de torreperogil (jaén, cuenca del guadalquivir oriental): Evidencias de deformacion tectonica en el área epicentral, Revista de la Sociedad Geologica de España, 27, 301-318.

Trugman, D. T. \& Shearer, P. M., 2017. GrowClust: A Hierarchical Clustering Algorithm for Relative Earthquake Relocation, with Application to the Spanish Springs and Sheldon, Nevada, Earthquake Sequences, Seismological Research Letters, 88(2A), 379-391.

Umakoshi, K., Takamura, N., Shinzato, N., Uchida, K., Matsuwo, N., \& Shimizu, H., 2008. Seismicity associated with the 1991-1995 dome growth at unzen volcano, japan, Journal of Volcanology and Geothermal Research, 175(1), 91 - 99, Scientific drilling at Mount Unzen.

Virtanen, P., Gommers, R., Oliphant, T. E., Haberland, M., Reddy, T., Cournapeau, D., Burovski, E., Peterson, P., Weckesser, W., Bright, J., van der Walt, S. J., Brett, M., Wilson, J., Millman, K. J., Mayorov, N., Nelson, A. R. J., Jones, E., Kern, R., Larson, E., Carey, C. J., Polat, İ., Feng, Y., Moore, E. W., VanderPlas, J., Laxalde, D., Perktold, J., Cimrman, R., Henriksen, I., Quintero, E. A., Harris, C. R., Archibald, A. M., Ribeiro, A. H., Pedregosa, F., van Mulbregt, P., \& SciPy 1.0 Contributors, 2020. SciPy 1.0: Fundamental Algorithms for Scientific Computing in Python, Nature Methods, 17, 261-272.

Vuan, A., Sugan, M., Amati, G., \& Kato, A., 2018. Improving the Detection of Low-Magnitude Seismicity Preceding the Mw 6.3 L'Aquila Earthquake: Development of a Scalable Code Based on the Cross Correlation of Template Earthquakes, Bulletin of the Seismological Society of America, 108(1), 471-480. Waldhauser, F. \& Ellsworth, W. L., 2000. A Double-Difference Earthquake Location Algorithm: Method and Application to the Northern Hayward Fault, California, Bulletin of the Seismological Society of America, 90(6), 1353-1368. 
Werner-Allen, G., Dawson-Haggerty, S., \& Welsh, M., 2008. Lance: Optimizing high-resolution signal collection in wireless sensor networks, in Proceedings of the 6th ACM Conference on Embedded Network Sensor Systems, SenSys '08, p. 169-182, Association for Computing Machinery, New York, NY, USA. Yazdi, P., Hainzl, S., \& Gaspar-Escribano, J. M., 2017. Statistical analysis of the 2012-2013 torreperogilsabiote seismic series, spain, Journal of Seismology, 21(4), 705-717.

Zhu, W. \& Beroza, G. C., 2018. PhaseNet: a deep-neural-network-based seismic arrival-time picking method, Geophysical Journal International, 216(1), 261-273. 